\title{
Experienced sitting-related problems and association with personal, lesion and wheelchair characteristics in persons with long-standing paraplegia and tetraplegia
}

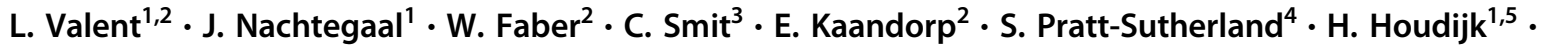 \\ J. Adriaansen ${ }^{6} \cdot$ ALLRISC $\cdot$ S. Groot de $^{6,7} \cdot$ M. W. M. Post ${ }^{8,9}$
}

Received: 21 July 2018 / Revised: 10 March 2019 / Accepted: 11 March 2019 / Published online: 15 April 2019

(c) International Spinal Cord Society 2019

\begin{abstract}
Study Design Cross-sectional study.

Objectives To describe experienced sitting-related health and stability problems among persons with paraplegia (PP) or tetraplegia (TP) and to investigate associations with personal, lesion and wheelchair characteristics as well as satisfaction with sitting posture.

Setting Dutch community.

Methods A self-report questionnaire on seating was developed and completed by wheelchair-users living with Spinal Cord Injury (SCI) for $\geq 10$ years $(N=264)$. Sitting-related problems and satisfaction with sitting posture were compared between participants with PP and TP using Chi-square and $t$-tests. Logistic regression analyses were performed to investigate associated characteristics.

Results Reported sitting-related problems comprised: sitting to be tiring (regularly to always) (33\%), sitting to be painful $(28 \%)$, pressure ulcers in the last three months (29\%), instability while sitting (8\%) and instability during reaching (33\%). Except for instability during reaching, no differences in occurrence of sitting-problems were found between lesion-group. Persons with TP were more dissatisfied with their sitting posture than persons with PP: $51 \%$ vs $36 \%(p=0.022)$ and $51 \%$ and $47 \%$ respectively thought their sitting posture could be improved $(p=0.670)$. 'Experienced lack of support in the wheelchair' was associated with most sitting-problems. Pain and instability were associated with dissatisfaction with sitting posture.

Conclusion Sitting-related problems and dissatisfaction with sitting posture were frequently reported by persons with longstanding SCI. Sitting problems appeared to associate with lacking support in the wheelchair/seating. A comprehensive feedback from the wheelchair user and a stability check (reach task), as part of the wheelchair/seating-user fitting, may contribute to prevention of sitting-related problems.
\end{abstract}

\section{Introduction}

The importance of proper seating has been addressed by Hastings et al. [1]. who stated that: 'Seating is the

Members of ALLRISC are listed in Acknowledgements.

Supplementary information The online version of this article (https:// doi.org/10.1038/s41393-019-0272-6) contains supplementary material, which is available to authorized users.

L. Valent

1.valent@heliomare.nl

Extended author information available on the last page of the article foundation for optimal outcomes in the spinal cord injury (SCI) -population, especially for those who use wheelchairs for fulltime-mobility'. Persons with SCI who lack walking ability, spend on average $9-11 \mathrm{~h}$ in their wheelchair daily [2]. Secondary health problems may occur as an (in)direct consequence of the SCI but they may also be caused, aggravated or sustained by an improper sitting posture for a prolonged time. Commonly reported sitting-related health problems by persons with SCI are: pressure ulcers, spinal deformities [3, 4], respiratory complaints, (lower) back pain $[3,5]$, neck pain [6] weight gain, chronic musculoskeletal pain $[4,7]$ and fatigue $[8,9]$.

It is important to monitor experienced sitting problems such as instability and discomfort in order to prevent or 
decrease secondary health problems, which ultimately are known to have a large impact on physical activity, participation and quality of life $[10,11]$. Stability problems such as falling forward or sideward may not always be noticed during sitting but may appear during an activity, e.g., reaching with the arms and these problems may hamper functioning [11].

Personal, lesion and wheelchair/interface characteristics may affect sitting and contribute to sitting problems (Fig. 1): Aging and age-associated health complications such as osteoporosis [12] and increased thoracic kyphosis [13] may challenge sitting, as well as anthropometric characteristics, such as waist circumference and gender differences. The level and completeness of the SCI determines the degree of paralysis, sensation, muscle atrophy, disturbance of blood supply to the buttocks [13], and the ability to lift or change seated posture, which may all influence sitting tolerance. The type of wheelchair determines the possibility to change sitting position. In contrast to hand rim wheelchairs, powered wheelchairs can be tilted as a whole and the backrest can be reclined $[1,14]$. The time spent daily in the wheelchair may also be associated with sitting problems. Moreover, the age at onset and time since onset of SCI may play a role as problems might accumulate over time. Lastly, the support provided from the seating system has a strong relationship with the posture of a seated paralyzed body [1].

It is unclear to what extent sitting-related problems and dissatisfaction with seating are prevalent among persons with SCI. Literature on seating and sitting-related problems in SCI is scarce and sample sizes are small [2, 3, 11, 12, 1418]. Moreover, results of some studies [12, 15, 17, 18] may have been biased as people with sitting-related problems were probably more willing to participate. Two studies reported only $40 \%$ of the participants being satisfied with their sitting posture $[3,12]$ whereas another study reported $68 \%$ to be satisfied with seating comfort.
Besides from this information, the frequency and severity of sitting related problems and their association with personal, lesion and wheelchair characteristics is unknown as well as the relationship between sitting-related problems and (dis)satisfaction with seating. Therefore, the aims of this current study with a cohort of persons, representing the Dutch chronic SCI-population (with time since injury $>10$ years) were to investigate:

1. The frequency of experienced sitting-related health and stability problems among persons with paraplegia (PP) and tetraplegia (TP).

2. a) Associations between sitting-related stability problems (experienced during sitting and reaching) and personal, lesion and wheelchair characteristics.

b) Associations between sitting-related health problems (experienced pain, fatigue, pressure ulcers and respiration) and personal, lesion and wheelchair characteristics as well as sitting-related stability problems.

3. Satisfaction with seated posture in both lesion groups and how this is related with sitting-related problems.

\section{Methods}

\section{Participants}

Former patients $(N=282)$ of the eight Dutch rehabilitation centers with a SCI unit participated, as part of the Dutch multicenter research program Active Lifestyle Rehabilitation Interventions in aging SCI, (ALLRISC) [19]. Participants were eligible if they were manual or powered wheelchair users, had their SCI for $>10$ years, were
Fig. 1 Model with health and stability problems, (personal, lesion and wheelchair) characteristics and satisfaction about seating

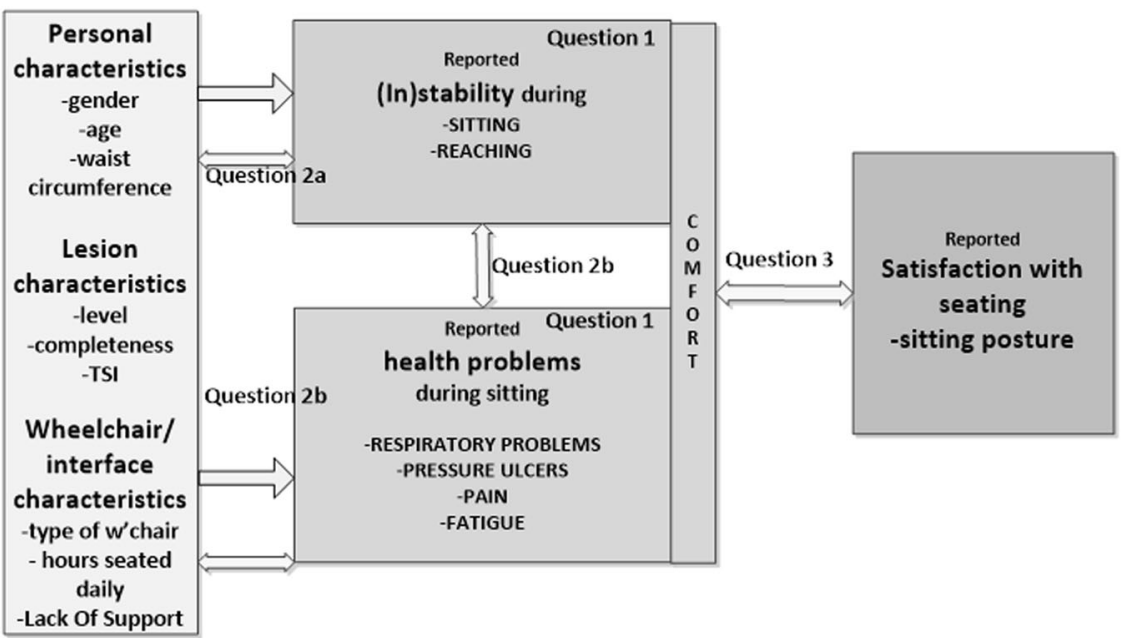


$\geq 18$ years old at onset of SCI, and between 28-65 years at time of inclusion [20]. People with insufficient mastery of the Dutch language or SCI due to malignancy were excluded as well as those who did not fill out the seating-related questionnaire.

\section{Outcome measures}

A seating questionnaire (Appendix) was used to measure sitting related health problems, instability, and satisfaction with seating. The questionnaire was developed in collaboration with content experts and appropriateness was checked by administering the draft questionnaire to three former patients with SCI. The sitting-related health problems pain, fatigue, and respiratory problems were scored on a 5 point scale (1: never, 2: sometimes, 3: regularly, 4: often and 5: always). For this study, scores were dichotomized into 'regularly to always pain': 1 and 'never to sometimes pain': 0. Experienced instability during sitting was dichotomized into yes: 1 (moderately stable - no stability) or no: 0 (stable) and instability during reaching was recoded into yes: 1 (falling forward, sideways etc.), and no: 0 . Lack of support of the wheelchair (LOS) was defined as yes: 1 or no: 0 . LOS was reported missing for respondents answering 'don't know' $(n=29)$. Dissatisfaction with sitting posture is dichotomized into yes: 1 (fair - very poor), or no: 0 (excellent - good).

Pressure ulcers (PU) at all locations were defined by rehabilitation physicians as present: 1 or absent: 0 in the last three months at one (or more) of the following locations: the heel, ankle, hips, ischial tuberosity, or sacral region.

Personal characteristics are age (years), gender (male: 0 and female: 1) and waist circumference (WC). WC was measured three times at one occasion with a measuring tape, at the level of the belly button and in supine position. The mean of the three measurements $(\mathrm{cm})$ was used for the analyses.

The lesion characteristics motor completeness, according to the Asia Impairment Score (AIS) (A or B: 1 vs. C or D: 0) and lesion level (TP: 0 and PP: 1), as well as time since injury (TSI) were determined by rehabilitation physicians.

Wheelchair/interface characteristics with type of wheelchair: powered wheelchair only (P-WCH): 1 vs. hand rim wheelchair only (HR-WCH): 0 . 'Hours seated daily' in the (hand rim and powered) wheelchair. We decided to treat the outcome measure (and sitting problem) LOS by the wheelchair as a wheelchair-user/interface characteristic as it describes the experienced fitting of the seating system to the body and we want to investigate possible associations of LOS with the sitting-related health and stability problems (shown in Fig. 1).

\section{Statistical analyses}

Chi-square and two samples independent t-tests were performed to compare the frequency of sitting-related problems (question 1) and (dis)satisfaction (question 3) between PP and TP. To answer question $2 \mathrm{a}$, the association between sitting stability problems (during sitting and reaching) and personal/lesion and wheelchair/interface-determinants (see Fig. 1) was investigated using univariate binary logistic regression analyses. In question $2 b$, the association of predominant sitting-related health problems (pain, fatigue, PU) and personal/lesion and wheelchair determinants as well as stability-determinants (see Fig. 1) was investigated. The association between sitting problems and (dis)satisfaction (question 3) was analyzed in as similar fashion as described for question 2. Data were analyzed using SPSS 23 software.

\section{Results}

Questionnaires were filled in by 264 out of 282 participants who participated in the ALLRISC cross sectional study ( 575 persons with SCI were approached) [20].

\section{Personal, lesion and wheelchair/interface characteristics of the sample}

The two groups (PP/TP) differed significantly, with more men and more participants with incomplete lesions in TP vs. PP (Table 1). Almost all participants with PP used a HRWCH. In the TP-group, $61 \%$ used a HR-WCH, $26 \%$ used a powered wheelchair $(\mathrm{P}-\mathrm{WCH})$ and $13 \%$ used both. Only a small, not statistically significant, difference was found between lesion groups in time spent in their HR-WCH.

\section{The frequency of experienced sitting-related problems}

In Table 2, all sitting-related problems are reported, including LOS, which may be seen as both a sitting problem and a wheelchair-user interface characteristic. No difference in experienced LOS in the wheelchair was found between participants with PP and TP (Table 2). Of participants experiencing LOS ( $n=47,18 \%, 95 \%$ CI: $13-22 \%), 42$ had AIS AB. In PP $(n=24)$ the three most reported body locations were: the lower back $(12 \times)$, lateral to lower back $(9 \times)$ and back at shoulder level $(8 \times)$. In TP $(n=23)$ support was lacking lateral to chest $(10 \times)$, lower back $(7 \times)$, and lateral lower back $(6 \times)$.

Significantly more participants with TP (89\%) compared to participants with PP (73\%) had (one or more) sitting related problem(s) e.g. pain or fatigue or PU or stability problems (Table 2). 
Table 1 Personal, lesion and wheelchair characteristics of participants with PP and TP

\begin{tabular}{|c|c|c|c|}
\hline$N=263^{\mathrm{a}}$ & $\begin{array}{l}\text { Paraplegia }(N= \\
157)\end{array}$ & $\begin{array}{l}\text { Tetraplegia } \\
(N=106)\end{array}$ & $p$-value \\
\hline \multicolumn{4}{|l|}{ Gender } \\
\hline Man & $107(68 \%)$ & $86(81 \%)$ & $0.017^{\mathrm{b}}$ \\
\hline Woman & $50(32 \%)$ & $20(19 \%)$ & \\
\hline \multirow[t]{2}{*}{ Lesion level } & Th1-6: 95 (61\%) & C5-6: $75(71 \%)$ & NA \\
\hline & $\leq$ Th7: $62(39 \%)$ & C7-8: $31(29 \%)$ & \\
\hline AIS AB & $135(86 \%)$ & $80(75 \%)$ & \\
\hline AIS CD & $22(14 \%)$ & $26(25 \%)$ & $0.033^{\mathrm{b}}$ \\
\hline Age (yrs: mean;SD) & $49 \pm 9$ & $48 \pm 8.5$ & 0.305 \\
\hline (yrs: median; IQRI) & $49 ; 13.5$ & $46.5,14$ & \\
\hline TSI (yrs: mean;SD) & $24 \pm 9.5$ & $24 \pm 8.5$ & 0.990 \\
\hline (yrs: median, IQR) & $22 ; 14.5$ & 23,13 & \\
\hline $\begin{array}{l}\text { Waist circumference } \\
(\mathrm{cm})\end{array}$ & $96.0 \pm 14.0$ & $99.7 \pm 16.0$ & 0.059 \\
\hline $\mathrm{HR}-\mathrm{WCH}$ & $146(93 \%)$ & $65(61 \%)$ & $<0.001^{\mathrm{b}}$ \\
\hline $\mathrm{P}-\mathrm{WCH}$ & $2(1 \%)$ & $27(26 \%)$ & \\
\hline Own both & $9(6 \%)$ & $14(13 \%)$ & \\
\hline $\begin{array}{l}\text { Hours spend in } \\
\text { wheelchair: }\end{array}$ & N Hours/day & N Hours/day & \\
\hline HR- WCH & $146: 13 \pm 3.5$ & $65: 14 \pm 3$ & 0.087 \\
\hline $\mathrm{P}-\mathrm{WCH}$ & 1: 16 & $25: 13 \pm 3$ & NA \\
\hline \multicolumn{4}{|l|}{ Both: } \\
\hline HR- WCH & $3^{c}: 6 \pm 5$ & $13: 10 \pm 5$ & NA \\
\hline $\mathrm{P}-\mathrm{WCH}$ & $4.5 \pm 4$ & $8 \pm 5.5$ & \\
\hline
\end{tabular}

AIS ASIA Impairment Scale, TSI Time Since Injury, $H R$ - $W C H$ hand rim wheelchair, $P-W C H$ Powered wheelchair, $N A$ Not Available.

${ }^{a}$ One participant with missing data on lesion

bsignificant $p$-value

${ }^{c}$ Hours/day not available in 6 persons

\section{Pain}

Of all participants, $28 \%$ reported 'regularly - always' pain. No difference in frequency of pain was found between PP and TP $(p=0.337)$. The three most reported pain locations with moderately to very severe pain are: 'neck' (TP: $10 \%$, PP: 13\%), 'upper back' (TP: 14\%, PP: 20\%), and 'lower back' (TP: 12\%, PP: 23\%) as is shown in Table 2. The lower back was the only location indicating differences in pain between participants with PP and TP $(p=0.052)$ and looking into 'moderate to very severe pain' significantly more pain was found in participants with PP $(p=0.025)$.

\section{Fatigue}

Of all participants, $33 \%$ reported sitting to be regularly always tiring: No differences were found in fatigue between persons with PP and TP $(p=0.803$, Table 2$)$.

\section{Respiratory problems}

Difficulty with breathing during sitting was rarely experienced (Table 2): 6 out of 106 persons $(6 \%)$ in TP and 5 out of 157 persons $(3 \%)$ in $\mathrm{PP}$.

\section{Pressure ulcers}

A total of 75 out of 263 persons (29\%) had an episode of PU in the past three months (Table 2). Fifty-six out of these 75 participants $(75 \%)$ reported PU in the buttocks (hips, ischial tuberosity or sacral region) with $12 \%$ grade $1,56 \%$ grade $2,14 \%$ grade 3 , and $11 \%$ grade 4 . As a consequence of PU people were restricted in sitting duration (Table 2). There were no significant differences in PU occurrence between persons with PP and TP.

\section{Instability during normal sitting}

Moderate stability and instability in the wheelchair was reported by 37 and $8 \%$ of all participants, respectively (Table 2). There was no significant difference between participants with TP and PP, only a trend was found for more instability in participants with $\mathrm{TP}(p=0.055)$.

\section{Instability during reaching}

Of all participants, $32 \%$ reported instability during reaching. Within PP, respectively 15,5 and $4 \%$ reported falling forwards, falling aside or both and within TP this was reported by 28,9 and $8 \%$. There was a significant difference between people with $\mathrm{PP}$ and with TP in experiencing instability during reaching $(p<0.001)$.

\section{Associations between sitting-related stability problems and characteristics}

\section{Instability during sitting}

Table $3 \mathrm{a}$ presents the results of analyzing the association between personal, lesion and wheelchair/interface characteristics with sitting related stability problems. Among persons with PP, LOS and hours seated daily were associated with sitting instability (upper part of Table 3a). The results for persons with TP were different; with every hour increase, the odds of experiencing instability were 0.72 times lower and with every year increase in age the odds were 1.06 times higher.

\section{Instability during reaching}

In the lower part of Table 3a, the univariate analyses showed that within the PP-group the odds for experiencing instability 
Table 2 Number (\%) of persons with PP and TP experiencing problems related to sitting

\begin{tabular}{|c|c|c|c|c|c|c|c|}
\hline \multirow[t]{2}{*}{ Experienced Sitting-related problems } & \multicolumn{2}{|c|}{ Paraplegia $(N=157)$} & \multicolumn{2}{|c|}{ Tetraplegia $(N=106)$} & \multicolumn{2}{|c|}{$\mathrm{PP}$ and $\mathrm{TP}(N=263)$} & \multirow[t]{2}{*}{$p$-value } \\
\hline & $N$ & $\%(95 \% \mathrm{CI})$ & $N$ & $\%(95 \% \mathrm{CI})$ & $N$ & $\%(95 \% \mathrm{CI})$ & \\
\hline \multicolumn{8}{|l|}{ Pain occurence: } \\
\hline Never & 49 & $31(24-38)$ & 29 & $27(19-35)$ & 78 & $30(24-36)$ & \multirow[t]{3}{*}{0.337} \\
\hline Sometimes & 61 & $39(31-47)$ & 51 & $48(38-58)$ & 112 & $42(36-48)$ & \\
\hline Regularly - always & 47 & $30(23-37)$ & 26 & $25(17-33)$ & 73 & $28(23-33)$ & \\
\hline \multicolumn{8}{|l|}{ Pain locations and severity } \\
\hline \multicolumn{8}{|l|}{ Neck } \\
\hline No pain & 55 & $35(28-42)$ & 31 & $29(20-38)$ & 86 & $33(27-39)$ & \multirow[t]{3}{*}{0.402} \\
\hline Not-somewhat severe & 81 & $52(44-60)$ & 65 & $61(52-70)$ & 146 & $55(49-61)$ & \\
\hline Moderately-very severe & 21 & $13(8-18)$ & 10 & $10(4-16)$ & 31 & $12(8-16)$ & \\
\hline \multicolumn{8}{|l|}{ Upper back } \\
\hline No pain & 54 & $34(27-41)$ & 31 & $29(20-38)$ & 85 & $32(26-38)$ & \multirow[t]{3}{*}{0.291} \\
\hline Not-somewhat severe & 72 & $46(38-54)$ & 60 & $57(48-66)$ & 132 & $50(44-56)$ & \\
\hline Moderately-very severe & 31 & $20(14-26)$ & 15 & $14(7-21)$ & 46 & $18(13-23)$ & \\
\hline \multicolumn{8}{|l|}{ Lower back } \\
\hline No pain & 51 & $32(25-39)$ & 32 & $30(21-39)$ & 83 & $32(26-38)$ & \multirow[t]{3}{*}{0.052} \\
\hline Not-somewhat severe & 70 & $45(37-53)$ & 61 & $58(49-67)$ & 131 & $50(44-56)$ & \\
\hline Moderately-very severe & 36 & $23(16-30)$ & 13 & $12(6-18)$ & 49 & $19(14-24)$ & \\
\hline \multicolumn{8}{|l|}{ Side thorax } \\
\hline No pain & 57 & $36(28-44)$ & 31 & $29(20-38)$ & 88 & $33(27-39)$ & \multirow[t]{3}{*}{0.455} \\
\hline Not somewhat severe & 94 & $60(52-68)$ & 73 & $69(60-78)$ & 167 & $63(57-69)$ & \\
\hline Moderately-very severe & 6 & $4(1-7)$ & 2 & $2(0-5)$ & 8 & $3(1-5)$ & \\
\hline \multicolumn{8}{|l|}{ Side lower back } \\
\hline No pain & 58 & $37(29-45)$ & 32 & $30(21-39)$ & 90 & $34(28-40)$ & \multirow[t]{3}{*}{0.708} \\
\hline Not-somewhat severe & 93 & $59(51-67)$ & 68 & $64(55-73)$ & 161 & $61(55-67)$ & \\
\hline Moderately-very severe & 6 & $4(1-7)$ & 6 & $6(1-11)$ & 12 & $5(2-8)$ & \\
\hline \multicolumn{8}{|l|}{ Ischial tuberosity } \\
\hline No pain & 59 & $38(30-46)$ & 34 & $32(23-41)$ & 93 & $35(29-41)$ & \multirow[t]{3}{*}{0.151} \\
\hline Not-somewhat severe & 78 & $49(41-57)$ & 65 & $61(52-70)$ & 143 & $55(49-61)$ & \\
\hline Moderately-very severe & 20 & $13(8-18)$ & 6 & $7(2-12)$ & 26 & $10(6-14)$ & \\
\hline \multicolumn{8}{|l|}{ Coxxyc } \\
\hline No pain & 60 & $38(30-46)$ & 32 & $30(21-39)$ & 92 & $35(29-41)$ & 0.413 \\
\hline Not-somewhat severe & 86 & $55(47-63)$ & 69 & $65(56-74)$ & 155 & $59(53-65)$ & \\
\hline Moderately-very severe & 11 & $7(3-11)$ & 5 & $5(1-9)$ & 16 & $6(3-9)$ & \\
\hline Fatigue: & & & & & & & \\
\hline Never & 24 & $15(9-21)$ & 17 & $16(9-23)$ & 41 & $16(12-20)$ & 0.803 \\
\hline Sometimes & 82 & $52(44-60)$ & 53 & $50(40-60)$ & 135 & $51(45-57)$ & \\
\hline Regularly - always & 51 & $33(26-40)$ & 36 & $34(25-43)$ & 87 & $33(27-39)$ & \\
\hline Respiratory problems: & & & & & & & \\
\hline Never & 133 & $85(79-91)$ & 76 & $72(63-81)$ & 209 & $79(74-84)$ & 0.325 \\
\hline Sometimes & 19 & $12(7-17)$ & 24 & $23(15-31)$ & 43 & $16(12-20)$ & \\
\hline Regularly-always & 5 & $3(0-6)$ & 6 & $5(1-9)$ & 11 & $5(2-8)$ & \\
\hline PU at one of all locations & 42 & $27(20-34)$ & 33 & $31(22-40)$ & 75 & $29(24-34)$ & 0.358 \\
\hline PU only at buttocks & 35 & $22(16-28)$ & 21 & $20(12-28)$ & 56 & $21(16-26)$ & 0.687 \\
\hline Bedrest due to sitting-related PU & 20 & $13(8-18)$ & 12 & $11(5-17)$ & 32 & $13(9-17)$ & 0.442 \\
\hline LOS in the wheelchair: & & & & & & & \\
\hline Yes & 24 & $15(9-21)$ & 23 & $22(14-30)$ & 47 & $18(13-23)$ & 0.904 \\
\hline
\end{tabular}


Table 2 (continued)

\begin{tabular}{|c|c|c|c|c|c|c|c|}
\hline \multirow[t]{2}{*}{ Experienced Sitting-related problems } & \multicolumn{2}{|c|}{ Paraplegia $(N=157)$} & \multicolumn{2}{|c|}{ Tetraplegia $(N=106)$} & \multicolumn{2}{|c|}{$\mathrm{PP}$ and $\mathrm{TP}(N=263)$} & \multirow[t]{2}{*}{$p$-value } \\
\hline & $N$ & $\%(95 \% \mathrm{CI})$ & $N$ & $\%(95 \% \mathrm{CI})$ & $N$ & $\%(95 \% \mathrm{CI})$ & \\
\hline No & 116 & $74(67-81)$ & 72 & $67(58-76)$ & 188 & $71(66-76)$ & \\
\hline Don't know & 17 & $11(6-16)$ & 12 & $11(5-17)$ & 29 & $11(7-15)$ & \\
\hline \multicolumn{8}{|l|}{ Stability in sitting: } \\
\hline Yes, Stable & 96 & $61(53-69)$ & 50 & $47(37-57)$ & 146 & $55(49-61)$ & 0.055 \\
\hline Moderate stability & 51 & $33(26-40)$ & 45 & $42(33-51)$ & 96 & $37(31-43)$ & \\
\hline Not stable at all & 10 & $6(2-10)$ & 12 & $11(5-17)$ & 22 & $8(5-11)$ & \\
\hline \multicolumn{8}{|l|}{ Stability in reaching: } \\
\hline Yes stable & 120 & $76(69-83)$ & 58 & $54(45-63)$ & 178 & $68(62-74)$ & $<0.001 *$ \\
\hline No falling forwards & 24 & $15(9-21)$ & 30 & $28(19-37)$ & 54 & $20(15-25)$ & \\
\hline No falling sideways & 7 & $5(2-8)$ & 10 & $9(4-14)$ & 17 & $6(3-9)$ & \\
\hline No falling others & 6 & $4(1-7)$ & 9 & $8(3-13)$ & 15 & $6(3-9)$ & \\
\hline One or more sitting- problems & 115 & $73(66-80)$ & 94 & $89(83-95)$ & 209 & $79(74-84)$ & $0.007 *$ \\
\hline
\end{tabular}

Abbreviations: $P U$ Pressure Ulcers (in the last three months), LOS Lack Of Support, *significant $p$-value

Table 3a Results of the univariate logistic analyses of; personal, lesion and wheelchair/interface characteristics associated with sitting-related stability problems

\begin{tabular}{|c|c|c|c|c|c|c|c|}
\hline \multirow[t]{2}{*}{ Stability problems } & \multirow{2}{*}{$\begin{array}{l}\text { Personal, lesion or wheelchair } \\
\text { characteristics }\end{array}$} & \multicolumn{3}{|c|}{ Paraplegia $(N=157)$} & \multicolumn{3}{|c|}{ Tetraplegia $(N=106)$} \\
\hline & & OR & $95 \% \mathrm{CI}$ & $p$-value & OR & $95 \% \mathrm{CI}$ & $p$-value \\
\hline \multirow[t]{8}{*}{ Instability sitting } & Gender (woman) & 2.0 & $1.0-3.9$ & 0.052 & 1.1 & $0.4-2.8$ & 0.903 \\
\hline & Age & 1.01 & $0.98-1.05$ & 0.555 & 1.06 & $1.01-1.12$ & $0.010 *$ \\
\hline & Waist circumference & 1.00 & $0.98-1.03$ & 0.864 & 0.98 & $0.96-1.00$ & 0.164 \\
\hline & TSI & 1.00 & $0.97-1.04$ & 0.772 & 1.04 & $1.00-1.09$ & 0.082 \\
\hline & Motor complete & 0.5 & $0.2-1.2$ & 0.108 & 0.4 & $0.2-1.1$ & 0.073 \\
\hline & Powered wheelchair & NA & & & 1.3 & $0.53-3.3$ & 0.543 \\
\hline & Hours seated daily & 0.89 & $0.81-0.98$ & $0.016 *$ & 0.72 & $0.59-0.87$ & $0.001 *$ \\
\hline & LOS in the wheelchair & 4.6 & $1.8-11.8$ & $0.001 *$ & 2.0 & $0.7-5.3$ & 0.169 \\
\hline \multirow[t]{8}{*}{ Instability reaching } & Gender (woman) & 2.2 & $1.0-4.8$ & 0.038 & 1.3 & $0.5-3.3$ & 0.638 \\
\hline & Age & 1.03 & $0.99-1.08$ & 0.969 & 1.00 & $0.96-1.05$ & 0.969 \\
\hline & Waist circumference & 1.01 & $0.98-1.04$ & 0.343 & 1.00 & $0.98-1.03$ & 0.991 \\
\hline & $T S I$ & 1.02 & $0.98-1.06$ & 0.265 & 0.99 & $0.95-1.04$ & 0.657 \\
\hline & Motor complete & 1.5 & $0.5-4.6$ & 0.523 & 3.7 & $1.3-10.1$ & $0.012 *$ \\
\hline & Powered wheelchair & NA & & & 8.6 & $2.9-25.8$ & $<0.01^{*}$ \\
\hline & Hours seated daily & 1.03 & $0.93-1.14$ & 0.598 & 0.89 & $0.78-1.02$ & 0.095 \\
\hline & LOS in the wheelchair & 4.3 & $1.7-11.1$ & $0.002 *$ & 2.0 & $0.8-5.3$ & 0.141 \\
\hline
\end{tabular}

TSI Time Since Injury, LOS Lack Of Support, NA Not Applicable, *significant $p$-value

during reaching was 4.3 times higher for people with LOS compared to people without LOS, and women had a 2.2. times higher odds to experience instability during reaching than men. For people with TP a 3.7 times higher odds of instability in motor complete lesion vs. incomplete lesion was found and a 8.6 times higher odds of instability in P-WCHusers compared to HR-WCH-users. The large confidence interval may be explained by the rather small group of powered wheelchair-users. Moreover, among persons with $\mathrm{TP}$, instability did not appear to be a rare event with 30 out of 65 experiencing instability in a HR-WCH, 15 out of 27 persons in a $\mathrm{P}-\mathrm{WCH}$ and 8 out of 14 persons using both.

\section{Associations between sitting-related health problems and characteristics}

\section{Pain}

In Table 3b, results from univariate analyses showed five significant associations within the PP-group for 'regular to always pain' (as compared to 'no-sometimes'): people with LOS had a 3.3 times higher odds to experience pain than people without, and women had a 2.3 times higher odds to have pain than men. With every centimeter increase in $\mathrm{WC}$, 
Table 3b Results of the univariate logistic analyses of personal, lesion and wheelchair/interface characteristics as well as stability-determinants associated with sitting-related health problems

\begin{tabular}{|c|c|c|c|c|c|c|c|}
\hline \multirow[t]{2}{*}{ Health problems } & \multirow{2}{*}{$\begin{array}{l}\text { Personal, lesion or wheelchair/interface } \\
\text { characteristics and stability-determinants }\end{array}$} & \multicolumn{3}{|c|}{ Paraplegia $(N=157)$} & \multicolumn{3}{|c|}{ Tetraplegia $(N=106)$} \\
\hline & & OR & $95 \% \mathrm{CI}$ & $p$-value & OR & $95 \%$ CI & $p$-value \\
\hline \multirow[t]{10}{*}{ Pain } & Gender (woman) & 2.3 & $1.0-4.6$ & $0.026^{*}$ & 1.0 & $0.3-3.2$ & 0.957 \\
\hline & Age & 1.01 & $0.97-1.05$ & 0.625 & 0.97 & $0.92-1.03$ & 0.330 \\
\hline & Waist circumference & 0.97 & $0.95-1.00$ & $0.036^{*}$ & 0.98 & $0.95-1.00$ & 0.143 \\
\hline & TSI & 0.99 & $0.96-1.03$ & 0.666 & 0.98 & $0.93-1.04$ & 0.502 \\
\hline & Motor complete & 0.9 & $0.3-2.4$ & 0.835 & 1.1 & $0.4-3.2$ & 0.843 \\
\hline & wheelchair (P-WCH) & NA & & & 1.4 & $0.5-4.0$ & 0.531 \\
\hline & Hours seated daily & 0.96 & $0.87-1.05$ & 0.353 & 0.94 & $0.82-1.09$ & 0.419 \\
\hline & LOS in the wheelchair & 3.3 & $1.3-8.2$ & $0.010^{*}$ & 4.6 & $1.6-12.8$ & $0.004 *$ \\
\hline & Instability sitting & 2.7 & $1.3-5.3$ & $0.006^{*}$ & 1.2 & $0.5-3.0$ & 0.645 \\
\hline & Instability reaching & 3.5 & $1.6-7.5$ & $0.002 *$ & 1.0 & $0.4-2.5$ & 0.918 \\
\hline \multirow[t]{10}{*}{ Fatigue } & Gender (woman) & 1.9 & $0.9-3.8$ & 0.084 & 1.1 & $0.4-2.9$ & 0.913 \\
\hline & Age & 1.03 & $0.99-1.07$ & 0.096 & 1.01 & $0.97-1.07$ & 0.490 \\
\hline & Waist circumference & 0.98 & $0.95-1.00$ & 0.059 & 0.97 & $0.94-0.99$ & $0.016^{*}$ \\
\hline & TSI & 1.01 & $0.98-1.05$ & 0.496 & 0.99 & $0.95-1.04$ & 0.744 \\
\hline & Motor complete & 1.3 & $0.5-3.6$ & 0.574 & 1.0 & $0.4-2.4$ & 0.935 \\
\hline & wheelchair (P-WCH) & NA & & & 1.8 & $0.7-4.5$ & 0.212 \\
\hline & Hours seated daily & 0.95 & $0.86-1.04$ & 0.222 & 0.78 & $0.66-0.91$ & $0.002^{*}$ \\
\hline & LOS in the wheelchair & 2.3 & $0.9-5.7$ & 0.066 & 4.7 & $1.7-12.6$ & $0.002^{*}$ \\
\hline & Instability sitting & 3.9 & $1.9-7.9$ & $<0.01 *$ & 3.3 & $1.4-7.8$ & $0.007 *$ \\
\hline & Instability reaching & 4.6 & $2.1-10.0$ & $<0.01 *$ & 3.2 & $1.4-7.4$ & $0.007 *$ \\
\hline \multirow{10}{*}{$\begin{array}{l}\text { Pressure ulcers In last } \\
3 \text { months }\end{array}$} & Gender (woman) & 1.2 & $0.6-2.5$ & 0.616 & 0.4 & $0.2-1.4$ & 0.177 \\
\hline & Age & 1.03 & $0.99-1.07$ & 0.154 & 0.98 & $0.94-1.03$ & 0.434 \\
\hline & Waist circumference & 0.98 & $0.96-1.00$ & 0.200 & 1.01 & $0.98-1.04$ & 0.552 \\
\hline & TSI & 1.00 & $0.97-1.05$ & 0.700 & 1.00 & $0.96-1.05$ & 0.917 \\
\hline & Motor complete & 9.5 & $1.2-72.8$ & $0.031 *$ & 2.5 & $0.9-7.4$ & 0.092 \\
\hline & wheelchair (P-WCH) & NA & & & 1.3 & $0.5-3.4$ & 0.560 \\
\hline & Hours seated daily & 0.99 & $0.90-1.09$ & 0.222 & 1.00 & $0.87-1.15$ & 0.990 \\
\hline & LOS in the wheelchair & 2.9 & $1.1-7.3$ & $0.021^{*}$ & 2.1 & $0.8-5.4$ & 0.134 \\
\hline & Instability sitting & 1.0 & $0.5-2.1$ & 0.914 & 1.0 & $0.5-2.3$ & 0.941 \\
\hline & Instability reaching & 1.0 & $0.4-2.2$ & 0.955 & 0.7 & $0.3-1.6$ & 0.444 \\
\hline
\end{tabular}

TSI Time Since Injury, $P$-WCH Powered Wheelchair, LOS Lack Of Support, NA Not Applicable, *significant $p$-value

the odds of experiencing pain were 0.97 times lower. Participants with PP experiencing 'instability during sitting' or 'instability during reaching' had respectively a 2.7 and 3.5 higher odds to experience pain. Within people with TP, LOS appeared the only significant determinant for experiencing regular-always pain with 4.6 times higher odds as compared to no LOS.

\section{Fatigue}

Univariate analyses (Table 3b) showed two significant associations in the PP-group for 'being regular-always fatigued' (as compared to 'no-sometimes'): Participants with 'instability in sitting' or 'instability in reaching' had respectively a 3.9 and 4.6 times higher odds to experience fatigue compared to people without instability in sitting or reaching.

In the TP-group, with every centimeter increase in $\mathrm{WC}$, the odds of experiencing fatigue were 0.97 times lower. The OR for participants with TP experiencing LOS to experience fatigue was 4.7 times higher compared to people without LOS. Participants with TP and 'instability in sitting' or 'instability in reaching' had respectively a 3.3 and 3.2 times higher odds to experience fatigue compared to those without instability. In the TP group, with every hour increase in hours seated daily, the odds of experiencing fatigue were 0.78 times lower.

\section{Pressure ulcers}

As Table $3 b$ shows, there are two significant associations in persons with PP for 'having PU' (as compared to no PU): the odds were 9.5 times higher for persons with motor complete lesion compared to people with an incomplete lesion, and people with LOS had a 2.9 times higher odds than people without LOS. In persons with TP, no significant associations were found. 


\section{Respiratory problems}

The number of participants experiencing this problem was too low to search for associations.

\section{Satisfaction with seating and the relation with sitting-related health and stability problems}

Of all participants, $58 \%$ judged their sitting posture to be 'excellent or good', 28\%: 'fair' and 14\% 'poor-very poor'. Of the $42 \%$ ( $n=111$ ) who judged their sitting posture to be 'fair - very poor', $72 \%(n=80)$ thought improvement was possible, $18 \%(n=20)$ did not know, and $10 \%(n=11)$ thought improvement was not possible.

Persons with TP were more dissatisfied with sitting posture than those with a PP: $51 \%$ compared to $36 \%$ ( $p=$ 0.022). 'Sitting posture can be improved' according to $47 \%$ of participants with PP and $51 \%$ of those with TP ( $p=$ 0.670 ), while respectively 24 and $25 \%$ did not know.

\section{Association with satisfaction and sitting-related problems}

In participants with $\mathrm{PP}$ and with $\mathrm{TP}$, the odds of being dissatisfied with their seating were respectively 4.7 and 3.1 times higher in those experiencing pain, shown in Table 4. In both lesion-groups, no significant associations were found between fatigue or PU and 'dissatisfaction with their seating'. Within the PP and TP-group, experiencing instability during sitting was significantly associated with 2.7 and 2.6 times higher odds for being dissatisfied with seating. The odds of being dissatisfied with their seating within the PP and TP-group were respectively 2.8 and 2.6 times higher for those reporting instability in reaching.

\section{Discussion}

Approximately $33 \%$ of the persons with longstanding SCI who use a wheelchair reported regularly occurring fatigue,

Table 4 Results of the univariate logistic regression analyses; associations between sitting-related health and stability problems and the dependent variable dissatisfaction with sitting posture

\begin{tabular}{|c|c|c|c|c|c|c|}
\hline \multirow{2}{*}{$\begin{array}{l}\text { Sitting-related } \\
\text { health and stability } \\
\text { problems }\end{array}$} & \multicolumn{3}{|c|}{ Paraplegia $(N=157)$} & \multicolumn{3}{|c|}{ Tetraplegia $(N=106)$} \\
\hline & OR & $95 \% \mathrm{CI}$ & $p$-value & OR & $95 \% \mathrm{CI}$ & $p$-value \\
\hline Instability sitting & 2.7 & $1.2-5.9$ & $0.016 *$ & 2.6 & $1.1-6.4$ & $0.033 *$ \\
\hline Instability reaching & 2.8 & $1.2-7.0$ & $0.024 *$ & 2.6 & $1.1-6.3$ & $0.038 *$ \\
\hline Pain & 4.7 & $1.8-11.9$ & $0.001 *$ & 3.1 & $1.0-9.9$ & $0.050 *$ \\
\hline Fatigue & 0.4 & $0.2-1.1$ & 0.082 & 1.8 & $0.7-5.1$ & 0.250 \\
\hline Pressure ulcers & 1.5 & $0.7-3.4$ & 0.335 & 1.2 & $0.5-3.0$ & 0.722 \\
\hline
\end{tabular}

*Sigificant $p$-value pain, pressure ulcers or instability during reaching. Moreover, only $21 \%$ experienced none of these sitting-problems. Sitting-related problems were sometimes related to personal or lesion characteristics but more often related to 'Lack of support offered by the wheelchair'. This finding may seem surprising as participants have already been in a wheelchair for decades. Also the fact that half of our participants thought improvement of sitting posture was still possible, supports the opinion that regular evaluation of the wheelchair-user seating interface is required in persons with longstanding SCI.

\section{Association of health and stability problems with characteristics}

Lack of support was associated most strongly with sitting related health and stability problems. It is important to emphasize that lack of support involves the fitting of the wheelchair-seating system to the wheelchair-user. In our group of participants, it is remarkable that a considerable number was still lacking support in their wheelchair or did not even know if support was lacking. The latter may be seen as an 'in between' answer (not completely lacking support but only in a specific situation) or may be explained by a loss of sensation and thus not feeling the (lack of) support from the wheelchair-seating to their body. Another explanation may be that some were not sure if they could benefit from more support.

In persons lacking support (or who didn't know), it may be possible that during the fitting-process of their current wheelchair the most optimal seating posture was not achieved. In the Netherlands the provision of the wheelchair is paid by the municipalities and performed by companies they work with. The time and money spend on the wheelchair selection and fitting-process may not always be sufficient and wheelchair users do not always get the wheelchair they want. Moreover, the companies doing the fitting are not always experienced with SCI or may not always involve the wheelchair user's experience. Lastly, especially in persons with longstanding SCI who are no longer in the picture of the SCI-units, specialized SCIseating therapist may not always have been involved in the process.

\section{Pain}

The odds of pain, mostly in the back or neck, increased in all persons who lacked support by their wheelchair e.g. in the back or lateral to the trunk. Interestingly in the group with TP, out of all characteristics tested, lack of support appeared to be the only one that was associated (strongly) with pain. This is in contrast with the PP group with several associations such as lack of support, instability in sitting and 
reaching, waist circumference and gender. It is interesting to note that in women within the PP-group the odds for having pain were higher compared to men. A possible explanation may be that inexperienced persons of companies tend to fit women in standard wheelchairs that are not ergonomically designed to their different anthropometric measures; for example in some women the pelvis width may exceed the chest width and if the back rest width is in conformity with the seat width, the lateral support to the chest and side becomes inadequate [1].

\section{Fatigue}

In persons with PP as well as TP the odds of sitting-related fatigue were higher when instability was experienced during sitting and/or reaching. In persons with TP, the odds of sitting-related fatigue was approximately five times higher when support was lacking in the wheelchair. This fatigue may be explained by the effect of gravity on the paralyzed body and the energy costs of the body to work against gravity. When no adequate fitting of the wheelchair to the user is realized, support may be lacking in the right locations and fatigue and/or (back) pain may occur [15, 17]. Vice-versa, there is support from literature that pain and discomfort may be reduced after interventions to the wheelchair $[15,17]$.

\section{Pressure ulcers}

Motor completeness of the lesion increased the odds of having pressure ulcers, which was also found by Adriaansen et al. within 5 years after discharge [21]. We found that lacking support was associated with higher odds of pressure ulcers, however, only in PP. A lack of support e.g. in the lower back may result in an undesirable sitting posture (backward rotated pelvis) with possibly unfavorable pressure distribution or shear forces [22].

\section{Instability in sitting and reaching}

Surprisingly, lack of support and instability in both sitting and reaching were not associated at all within the TP-group. Within TP, the odds of instability in reaching were especially higher in those with a powered wheelchair and a motor complete lesion. From our data, however, it appeared that powered wheelchair-users were mainly those with complete C5/C6 lesions while the hand rim users were C7/C8-lesions. Experienced instability may therefore be explained by less available arm (and trunk) function rather than the type of wheelchair. Instability during sitting appeared to increase with ageing in the TP-group and those experiencing more instability during sitting were probably not capable to sit long hours.
In contrast to TP, instability in sitting and reaching in the PP-group were both strongly associated with lack of support. It has to be borne in mind that our PP-group consisted of relatively more participants with complete lesions compared to the TP-group. On the other hand, stabilitychallenges may also have been less addressed during wheelchair/seating-customization in persons with PP compared to those with TP. Moreover, in clinical practice it is often seen that persons with PP deliberately choose less support (e.g. a lower back support/rest), to increase freedom of movement although this may also cause instability and fatigue. In women with PP the odds for experiencing instability were higher than in men and, just like in pain, individual customization may have been less optimal. Therefore, individual customization with adequate lateral $[12,14]$, and for- and backward stability of the trunk and pelvis [23] is important in both men and women with TP or PP to achieve postural alignment and stability without interfering with activities of daily life [12].

\section{Satisfaction with seating and the relation with sitting-related health and stability problems}

Persons with TP appeared significantly more dissatisfied with their sitting posture than persons with PP but, except for instability during reaching, no differences were found in occurrence of sitting-related problems between both groups. An even proportion in PP and TP indicated that their sitting posture could be improved $(\sim 50 \%)$ or did not know if improvement was possible $(25 \%)$. We found that pain and instability showed associations with dissatisfaction about sitting, whereas PU and fatigue did not. It is interesting to note that fatigue and instability were strongly associated in SCI but fatigue itself did not appear to be associated with dissatisfaction with seating, which might have to do with the advantage of freedom of movement.

\section{Limitations of the study}

It is important to note that sitting posture, support offered by the wheelchair and stability were not evaluated objectively. Nevertheless, to our opinion, the judgment of the wheelchair user is valuable as, to our knowledge, valid objective measurements of the support offered by the wheelchair and quality of sitting posture is not yet available, except for an effort by Hastings et al. to measure seating posture [14]. More research is needed but for now we agree with Alm et al. [12]. who states that: 'both an examiner's classification and subjects' evaluation sitting are necessary to obtain a sufficient knowledge base for subsequent adjustment'.

The questionnaire is still in development. There is limited generalizability as about half of the approached persons decided not to participate due to lack of time (mostly) or 
health issues. Moreover, the results can only be generalized to countries with comparable wheelchair-provision and healthcare-systems and to people with longstanding SCI.

\section{Implications for rehabilitation}

Current findings suggest that health- and stability problems in persons with longstanding SCI could be related to inadequate seating. From clinical practice it is known that a hands on mat evaluation is of importance for screening of (potential) sitting-related challenges. This study indicates that it may be helpful when the fitting of the user to the wheelchair/seating is checked in long-term wheelchair users with SCI and also includes: (1) comprehensive feedback from the wheelchair user about (lack of) support and (2) a stability check e.g. by reaching the arms forwards during an activity.

\section{Conclusions}

Approximately $33 \%$ of the persons with chronic SCI who use a wheelchair reported regularly occurring fatigue, pain, pressure ulcers and instability during reaching. We found that, out of all personal, lesion and wheelchair characteristics, 'reported lack of support in the wheelchair' appeared to associate with many sitting-related health and stability problems. Persons with TP were more dissatisfied with their seating outcomes than those with PP but half of the participants of both groups thought improvement in sitting posture was possible. Dissatisfaction in persons with SCI appeared to be related to pain and instability and not to fatigue and pressure ulcers.

\section{Data archiving}

The datasets generated and/or analyzed during the current study are available from the corresponding author on reasonable request.

Acknowledgements We thank all participants and all ALLRISC research assistants and SCI rehabilitation physicians for collecting all the data and the following participating Dutch rehabilitation centres: Rehabilitation Centre De Hoogstraat (Utrecht), Reade Centre for Rehabilitation (Amsterdam); Rehabilitation Centre Het Roessingh (Enschede); Adelante Rehabilitation Centre (Hoensbroek); Sint Maartenskliniek (Nijmegen); University Medical Centre Groningen, Centre for Rehabilitation-Beatrixoord (Haren); Rehabilitation Centre Heliomare (Wijk aan Zee) and Rijndam Rehabilitation Centre (Rotterdam).

ALLRISC members Lucas H.V. van der Woude $^{7}$, Jan van der Scheer ${ }^{10}$, Thomas W.J. Janssen ${ }^{11,12}$, Sonja de Groot ${ }^{12,13}$, Arjan Bakum ${ }^{14}$, Hans Bussmann $^{15}$, Hedwig Kooijmans ${ }^{15}$, Janneke Stolwijk ${ }^{16}$, Maurits Sloots $^{12}$, Dirk van Kuppevelt ${ }^{17}$, Hennie Rijken ${ }^{17}$, Willemijn Faber ${ }^{18}$, Linda Valent ${ }^{18}$, Govert Snoek ${ }^{19}$, Marijke Schuitemaker ${ }^{19}$, Marga
Tepper $^{20}$, Ferry Woldring ${ }^{20}$, Sandra Slangen ${ }^{21}$, Mia Wynants ${ }^{22}$, Rogier Broeksteeg $^{23}$, Peter Luthart ${ }^{22}$

${ }^{10}$ University of Groningen, University Medical Center Groningen, Center for Human Movement Sciences, Groningen, The Netherlands;

${ }^{11}$ MOVE Research Institute Amsterdam, Faculty of Human Movement Sciences, VU University, Amsterdam, The Netherlands; ${ }^{12}$ Amsterdam Rehabilitation Research Center/Reade, Amsterdam, The Netherlands; ${ }^{13}$ University of Groningen, University Medical Groningen, Groningen, The Netherlands; ${ }^{14}$ Faculty of Human Movement Sciences, VU University, Amsterdam, The Netherlands; ${ }^{15}$ Department of Rehabilitation Medicine and Physical Therapy, Erasmus MC University Medical Center, Rotterdam, The Netherlands; ${ }^{16}$ Department of Spinal Cord Injury, De Hoogstraat Rehabilitation, Utrecht, The Netherlands; ${ }^{17}$ Sint Maartenskliniek, Nijmegen, The Netherlands; ${ }^{18}$ Rehabilitation Center Heliomare, Wijk aan Zee, The Netherlands; ${ }^{19}$ Rehabilitation Center Het Roessingh, Enschede, The Netherlands; ${ }^{20}$ University Medical Center Groningen, Center for Rehabilitation, Department of Rehabilitation Medicine, Groningen, The Netherlands; ${ }^{21}$ Adelante Rehabilitation Center, Hoensbroek, The Netherlands; ${ }^{22}$ De Hoogstraat Rehabilitation, Utrecht, The Netherlands; ${ }^{23}$ Rijndam Rehabilitation Center, Rotterdam, The Netherlands

Author contributions LVA was responsible for developing the idea/ research question, developing the protocol for data analysis, statistical analysis, interpreting results, writing the report. JNA was responsible for developing the protocol for data analysis, statistical analysis, interpreting results, providing feedback on report. WFA was responsible for inclusion of participants, interpreting results, providing feedback on the report. CSM was responsible for inclusion of participants, interpreting results, providing feedback on the report. EKA was responsible for developing the idea/research question, interpreting results, providing feedback on the report. SPR was responsible for developing the idea and providing feedback on the report. HHO was responsible for developing the idea/research question, interpreting results, providing feedback on the report. JAD was responsible for developing of the protocol and dataset of ALLRISCproject and inclusion of participants. SGR was responsible for developing the idea/research question, interpreting results, providing feedback on the report. MWP was responsible for developing of the protocol and dataset of ALLRISC-project developing the idea/ research question, interpreting results, providing feedback on the report.

\section{Compliance with ethical standards}

Statement of Ethics We certify that all applicable institutional and governmental regulations concerning the ethical use of human volunteers were followed during the course of this research.

Conflict of interest The authors declare no conflicts of interest.

Publisher's note: Springer Nature remains neutral with regard to jurisdictional claims in published maps and institutional affiliations.

\section{References}

1. Hastings JDBKL Seating and Wheelchair Prescription. In: FieldFote EC, editor. Spinal Cord Injury Rehabilitation: F.A. Davis Company; 2009. p. 162.

2. Sonenblum SE, Sprigle SH, Martin JS. Everyday sitting behavior of full-time wheelchair users. J Rehabil Res Dev. 2016;53:585-98. 
3. Samuelsson. Back pain and spinal deformity: common among wheelchair users with spinal cord injuries. Scandjoccupther . 1996;1:28-32.

4. Boninger ML, Saur T, Trefler E, Hobson DA, Burdett R, Cooper RA. Postural changes with aging in tetraplegia: effects on life satisfaction and pain. Arch Phys Med Rehabil. 1998; 79:1577-81.

5. Michailidou C, Marston L, De Souza LH, Sutherland I. A systematic review of the prevalence of musculoskeletal pain, back and low back pain in people with spinal cord injury. Disabil Rehabil. 2014;36:705-15.

6. Boninger ML, Cooper RA, Fitzgerald SG, Lin J, Cooper R, Dicianno B, et al. Investigating neck pain in wheelchair users. Am J Phys Med Rehabil. 2003;82:197-202.

7. Pellegrini A, Pegreffi F, Paladini P, Verdano MA, Ceccarelli F, Porcellini G. Prevalence of shoulder discomfort in paraplegic subjects. Acta Biomed. 2012;83:177-82.

8. Anton HA, Miller WC, Townson AF, Imam B, Silverberg N, Forwell $\mathrm{S}$. The course of fatigue after acute spinal cord injury. Spinal Cord. 2017;55:94-7.

9. Lundstrom U, Wahman K, Seiger A, Gray DB, Isaksson G, Lilja M. Participation in activities and secondary health complications among persons aging with traumatic spinal cord injury. Spinal Cord. 2016;55:367-72.

10. Alschuler KN, Jensen MP, Sullivan-Singh SJ, Borson S, Smith AE, Molton IR. The association of age, pain, and fatigue with physical functioning and depressive symptoms in persons with spinal cord injury. J Spinal Cord Med. 2013;36:483-91.

11. Serra-Ano P, Pellicer-Chenoll M, Garcia-Masso X, Brizuela G, Garcia-Lucerga C, Gonzalez LM. Sitting balance and limits of stability in persons with paraplegia. Spinal Cord. 2013; 51:267-72.

12. Alm M, Gutierrez E, Hultling C, Saraste H. Clinical evaluation of seating in persons with complete thoracic spinal cord injury. Spinal Cord. 2003;41:563-71.

13. Hitzig SL, Eng JJ, Miller WC, Sakakibara BM. An evidencebased review of aging of the body systems following spinal cord injury. Spinal Cord. 2011;49:684-701.
14. Hastings JD, Fanucchi ER, Burns SP. Wheelchair configuration and postural alignment in persons with spinal cord injury. Arch Phys Med Rehabil. 2003;84:528-34.

15. Samuelsson K, Larsson H, Thyberg M, Gerdle B. Wheelchair seating intervention results a client-cent approach. Disabil Rehabil. 2001;23:677-82.

16. Aissaoui R, Boucher C, Bourbonnais D, Lacoste M, Dansereau J. Effect of seat cushion on dynamic stability in sitting during a reaching task in wheelchair users with paraplegia. Arch Phys Med Rehabil. 2001;82:274-81.

17. Belle M, Terracol C, Castel-Lacanal E, Le Floch G, Hidalgo S, Marque $\mathrm{P}$, et al. Evaluation of seating intervention effect for patient at Toulouse UniversityHospital's wheelchair seating clinic (WSC). Ann Phys Rehabil Med. 2016;59S:e27.

18. Mao HF, Huang SL, Lu TW, Lin YS, Liu HM, Wang YH, et al. Effects of lateral trunk support on scoliotic spinal alignment in persons with spinal cord injury: a radiographic study. Arch Phys Med Rehabil. 2006;87:764-71.

19. van der Woude LH, de Groot S, Postema K, Bussmann JB, Janssen TW, Post MW. Active Lifestyle Rehabilitation interventions in aging spinal cord injury (ALLRISC): a multicentre research program. Disabil Rehabil. 2013;35:1097-103.

20. Adriaansen JJ, van Asbeck FW, Lindeman E, van der Woude LH, de Groot S, Post MW. Secondary health conditions in persons with a spinal cord injury for at least 10 years: design of a comprehensive long-term cross-sectional study. Disabil Rehabil. 2013;35:1104-10.

21. Adriaansen JJ, Post MW, de Groot S, van Asbeck FW, StolwijkSwuste JM, Tepper M, et al. Secondary health conditions in persons with spinal cord injury: a longitudinal study from one to five years post-discharge. J Rehabil Med. 2013;45:1016-22.

22. Kobara K, Eguchi A, Watanabe S, Shinkoda K. The influence of the distance between the backrest of a chair and the position of the pelvis on the maximum pressure on the ischium and estimated shear force. Disabil Rehabil Assist Technol. 2008;3:285-91.

23. Hobson DA, Tooms RE. Seated lumbar/pelvic alignment. A comparison between spinal cord-injured and noninjured groups. Spine. 1992;17:293-8.

\section{Affiliations}

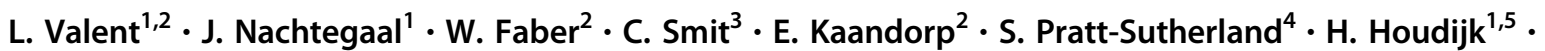
J. Adriaansen ${ }^{6} \cdot$ ALLRISC $\cdot$ S. Groot de $^{6,7} \cdot$ M. W. M. Post ${ }^{8,9}$

1 Research \& Development, Heliomare Rehabilitation Centre, Wijk aan Zee, The Netherlands

2 Spinal Cord Injury Department, Heliomare Rehabilitation Centre, Wijk aan Zee, The Netherlands

3 Rehabilitation Centre Tolbrug, Den Bosch, The Netherlands

4 Seating Solutions LL, Boulder, USA

5 Faculty of Behavioural and Human Movement Sciences, VU University Amsterdam, Amsterdam, The Netherlands

6 Amsterdam Rehabilitation Research Centre, Reade, Amsterdam, The Netherlands
7 Center for Human Movement Sciences, Center for Rehabilitation, Department of Rehabilitation Medicine, Groningen, The Netherlands

8 University of Groningen, University Medical Center Groningen, Center for Rehabilitation, Groningen, The Netherlands

9 Center of Excellence for Rehabilitation Medicine, Brain Center Rudolf Magnus, University Medical Center Utrecht and De Hoogstraat Rehabilitation, Utrecht, The Netherlands 